\title{
Clinical Research of Ultrasound Ciliary Plasty and Implications for Clinical Practice
}

\author{
Philippe Denis \\ Hospital Consultant and Head Ophthalmology Department, Croix-Rousse University Hospital, Lyon, France
}

$\mathrm{U}$ Itrasound ciliary plasty (UCP) is a novel, non-invasive procedure for the control of intraocular pressure (IOP) in patients with openangle glaucoma (OAG), and is particularly useful for refractory glaucoma after failed filtering surgery and patients with elevated risk of surgical failure due to high risk of conjunctival bleb scarring. A meta-analysis was performed of seven clinical trials, involving 251 patients, which evaluated the efficacy and safety of the procedure. The procedure was effective in reducing mean IOP across all indications and IOP reductions were similar in patients with refractory and non-refractory glaucoma. Safety and tolerability were good, with conjunctival hyperaemia being the most common side effect. Serious complications were rare. Procedures using the second-generation therapy probe were associated with superior reproducibility of IOP reduction compared with the first-generation probe. In summary, the procedure is a promising and effective treatment option for patients with refractory and non-refractory OAG.

\section{Keywords}

High-intensity focused ultrasound (HIFU), intraocular pressure (IOP), open-angle glaucoma (OAG), primary open-angle glaucoma (POAG), ciliary body, ultrasound ciliary plasty (UCP)

Disclosure: Philippe Denis has been a consultant to Alcon, Alimera, Allergan, Eye Tech Care, Istar and Théa, received travel support from Alcon, Alimera, Allergan, Eye Tech Care, Istar, MSD, Pfizer and Théa, and been a lecturer for Alcon, Alimera, Allergan, Eye Tech Care, Istar, MSD, Pfizer, Théa and Zeiss.

Acknowledgements: Medical writing assistance was provided by Catherine Amey at Touch Medical Media, UK, funded by Eye Tech Care.

Compliance with Ethics Guidelines: This metaanalysis involves a review of the literature and did not involve any studies with human or animal subjects performed by the author.

Authorship: All named authors meet the Internationa Committee of Medical Journal Editors (ICMJE) criteria for authorship of this manuscript, take responsibility for the integrity of the work as a whole, and have given final approval to the version to be published.

open Access: This article is published under the Creative Commons Attribution Noncommercial License, which permits any non-commercial use, distribution, adaptation and reproduction provided the original author(s) and source are given appropriate credit.

Received: 10 October 2016

Accepted: 2 November 2016

Citation: European Ophthalmic Review,

2016;10(2):108-12

Corresponding Author: Philippe Denis, Service d'Ophtalmologie - Bâtiment R, Hôpital de la Croix-Rousse 103, Grande Rue de la Croix-Rousse, 69317 LYON cédex 04,France. E: philippe.denis@chu-lyon.fr

Support: The publication of this article was supported by Eye Tech Care. The views and opinions expressed are those of the authors and do not necessarily reflect those of Eye Tech Care. The authors provided Eye Tech Care with the opportunity to review the article for scientific accuracy before submission. Any resulting changes were made at the author's discretion.
Interest in the application of ultrasound as treatment for glaucoma began in the 1980s. Following recent breakthroughs in the field of high-intensity focused ultrasound (HIFU) technology, a new procedure, known as ultrasound ciliary plasty (UCP) has been developed for selective, precise and gentle structural modification of the ciliary body, with sparing of the adjacent ocular structures. ${ }^{1-3}$ The procedure uses a sterile, single-use therapy probe and a positioning cone, and is performed as follows: with the patient lying in the supine position, a polymer coupling cone is positioned on the eye globe, achieving good placement of the six active piezoelectric elements (ultrasound transducers) with respect to distance and centration (see Figure 1). Contact with the eye is maintained through a low-level vacuum (225 $\mathrm{mmHg}$ ), which is applied by means of a suction ring at the cone base. A ring-shaped treatment probe (30 $\mathrm{mm}$ in diameter and $15 \mathrm{~mm}$ in height), which contains six transducers, is inserted in the upperportion of the coupling cone.

Three probe models with different diameters are available to account for differences in ocular anatomy. The probe size is determined for each patient, either by ultrasound bio-microscopy (UBM) imaging or optical coherence tomography (OCT) of the anterior segment or by biometry performed at baseline. ${ }^{3}$ The $4 \mathrm{ml}$ cavity that is created between the eye, cone and treatment probe is filled with sterile, saline solution at room temperature (BSS, Alcon Inc., Fort Worth, TX, US, or equivalent product). The six elliptical cylinder-shaped impacts are centred on an 11-13 $\mathrm{mm}$ diameter circle, depending on the ring diameter chosen, and spread over the eye circumference, while avoiding the nasal-temporal meridian. A second-generation probe has now been developed and differs from the original version in its broader active transducer area ( $4 \mathrm{~mm}$ instead of $2.5 \mathrm{~mm}$ ) and more precise temperature calibration of each single transducer. Other enhancements of the second-generation probe include: optimised suction and centring on the eye globe; improved coupling of ultrasound due to removal of air bubbles in the liquid which could disturb the ultrasound beam; optimised ergonomics and improved clip to attach the probe into the cone.

Several prospective clinical studies on UCP treatment have been performed with a follow-up of up to 12 months (see Table 1). These studies have all supported the effectiveness of the procedure in reducing intra-ocular pressure (IOP) in patients with glaucoma. ${ }^{4-9}$ This article describes a metaanalysis of the clinical trial data to date, with a focus on the second-generation probe compared with the previous one. In addition, patient outcome is compared for refractory patients after failed filtering surgery versus surgery naïve patients.

\section{Methods}

Data were pooled from seven clinical trials evaluating the first- or second-generation probe (five and two trials, respectively). Criteria for selection included refractory or non-refractory glaucoma patients with IOP $>21 \mathrm{mmHg}$. Refractory means that the patient had at least one failed attempt at filtering surgery. As per the study protocols, glaucoma medications were kept constant for at least 2 months after the procedure and could then be adjusted at the physician's discretion to 
Figure 1: High-intensity focused ultrasound device components
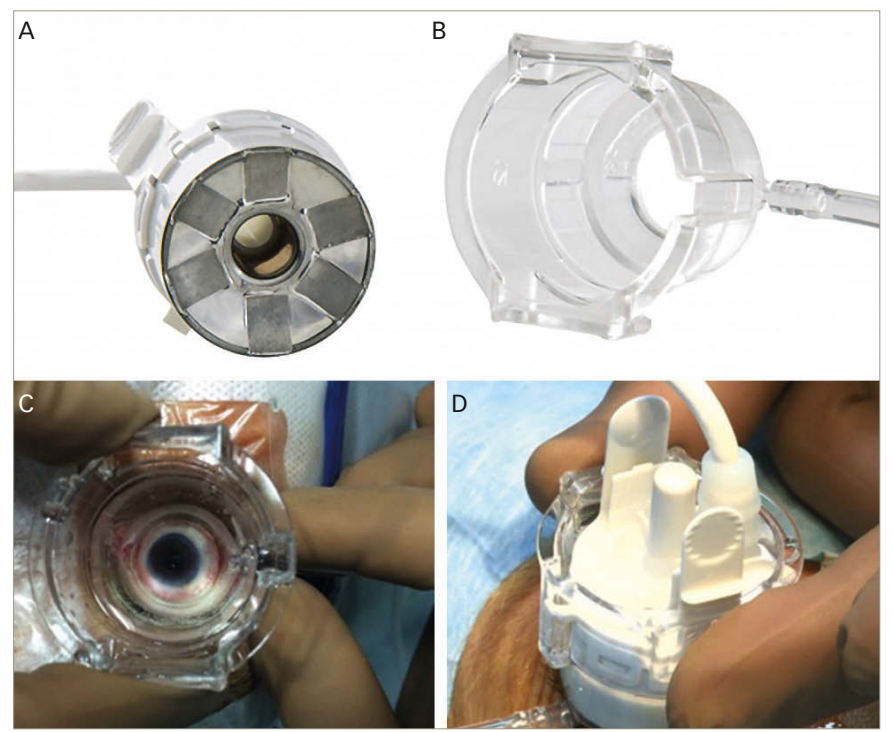

A: probe with six active piezoceramic transducers; $B$ : coupling cone; C: placement and centring of coupling cone; D: probe is inserted in coupling cone and the cavity filled with room temperature saline solution. Source: Eye Tech Care, Lyon, France.
Table 1: Overview of controlled clinical studies included in meta-analysis*

\begin{tabular}{|c|c|c|c|c|c|}
\hline $\begin{array}{l}\frac{\Phi}{0} \\
\frac{c}{\Phi} \\
\frac{\Phi}{\Phi} \\
\frac{\Phi}{\Psi}\end{array}$ & 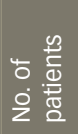 & 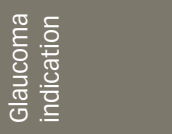 & 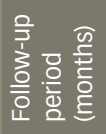 & 을 & $\begin{array}{l}\overline{8} \\
\frac{0}{ \pm} \\
\frac{ \pm}{ \pm} \\
\Sigma\end{array}$ \\
\hline $\begin{array}{l}\text { Denis et al. } \\
(2015)^{4}\end{array}$ & 52 & Refractory & 12 & First & $\begin{array}{l}\text { Prospective, } \\
\text { multicentre }\end{array}$ \\
\hline $\begin{array}{l}\text { Melamed et al. } \\
(2015)^{5}\end{array}$ & 20 & Refractory & 12 & First & $\begin{array}{l}\text { Prospective, } \\
\text { single centre }\end{array}$ \\
\hline $\begin{array}{l}\text { Aptel et al. } \\
(2014)^{6}\end{array}$ & 28 & Refractory & $6-12$ & First & $\begin{array}{l}\text { Prospective, } \\
\text { multicentre }\end{array}$ \\
\hline $\begin{array}{l}\text { Fogagnolo et al. } \\
(2013)^{9}\end{array}$ & 11 & Refractory & 12 & First & $\begin{array}{l}\text { Prospective, } \\
\text { single centre }\end{array}$ \\
\hline $\begin{array}{l}\text { Aptel et al. } \\
(2015)^{8}\end{array}$ & 30 & Non-refractory & 12 & First & $\begin{array}{l}\text { Prospective, } \\
\text { multicentre }\end{array}$ \\
\hline $\begin{array}{l}\text { Rouland et al. } \\
(2015)^{7}\end{array}$ & 20 & $\begin{array}{l}\text { Refractory + } \\
\text { non-refractory }\end{array}$ & $6-12$ & Second & $\begin{array}{l}\text { Prospective, } \\
\text { multicentre }\end{array}$ \\
\hline $\begin{array}{l}\text { ETC-IND-02 } \\
(2015)^{11}\end{array}$ & 90 & Non-refractory & 6 & Second & $\begin{array}{l}\text { Prospective, } \\
\text { Single centre }\end{array}$ \\
\hline
\end{tabular}

*Uncontrolled patient registry data were not included.

Figure 2: Mean intraocular pressure reductions for first- and second-generation probes - all indications

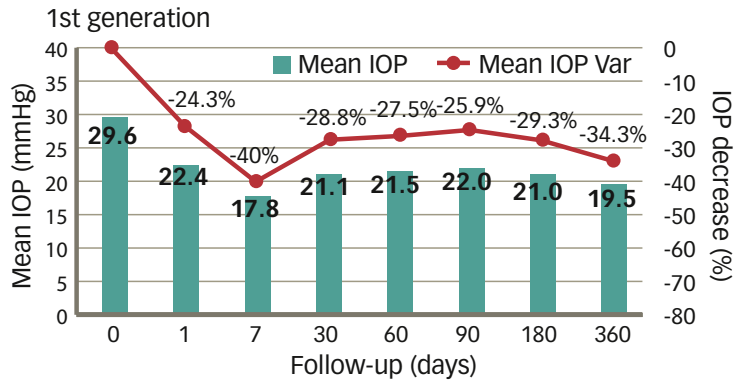

\begin{tabular}{llllllll} 
Base & D1 & D7 & M1 & M2 & M3 & M6 & M12 \\
\hline 141 & 135 & 141 & 138 & 93 & 126 & 117 & 95 \\
\hline 3.8 & 3.9 & 3.8 & 3.8 & 3.7 & 3.6 & 3.6 & 3.3
\end{tabular}

$I O P=$ intraocular pressure; Med = glaucoma medication; $P$ ts = patients; Var = variation.

achieve the target IOP. Patient response rate and IOP reduction were analysed by a chi-squared test for statistical significance.

\section{Results}

\section{Patients}

Collectively, data from 251 patients (160 male: 91 female) were included in the meta-analysis: 141 and 110 from the studies of the first- and second-generation probe, respectively. Out of the 251 patients, 133 (53\%) had refractory glaucoma and 118 (47\%) were naive of filtering surgery. The mean age of the patients was 63 years old (standard deviation \pm 13 years). The majority of patients (211 patients, $84 \%$ ) were diagnosed with primary open-angle glaucoma (OAG) and the remainder (40 patients, $16 \%)$ had secondary glaucoma. Of the studies analysing the secondgeneration probe ( $n=110), 90$ (82\%) patients were of Indian ethnicity.

\section{Efficacy}

The device, with either first- or second-generation probes, was effective in reducing the mean IOP across all indications (see Figure 2). As Figure 3 shows the average IOP reduction for the second-generation at 6-months follow-up was 35\% and thus higher than for the first-

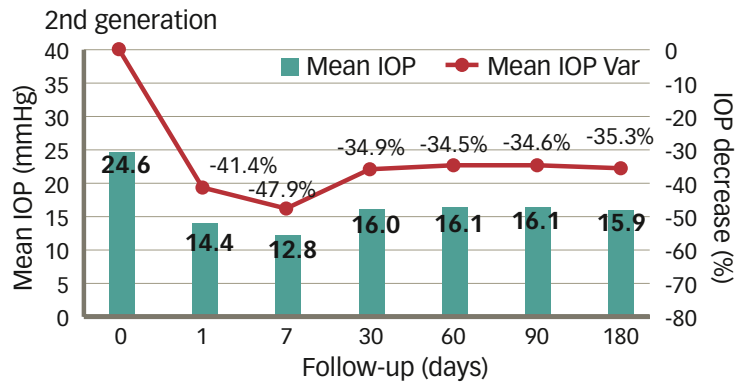

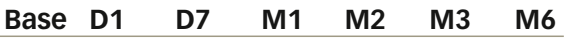

$\begin{array}{lllllll}110 & 93 & 107 & 109 & 95 & 108 & 101\end{array}$

$\begin{array}{lllllll}1.0 & 0.7 & 1.0 & 1.0 & 0.9 & 1.1 & 1.2\end{array}$

Figure 3: Average intraocular pressure decrease from baseline for all patients for first-generation compared with second-generation probe at 6 months

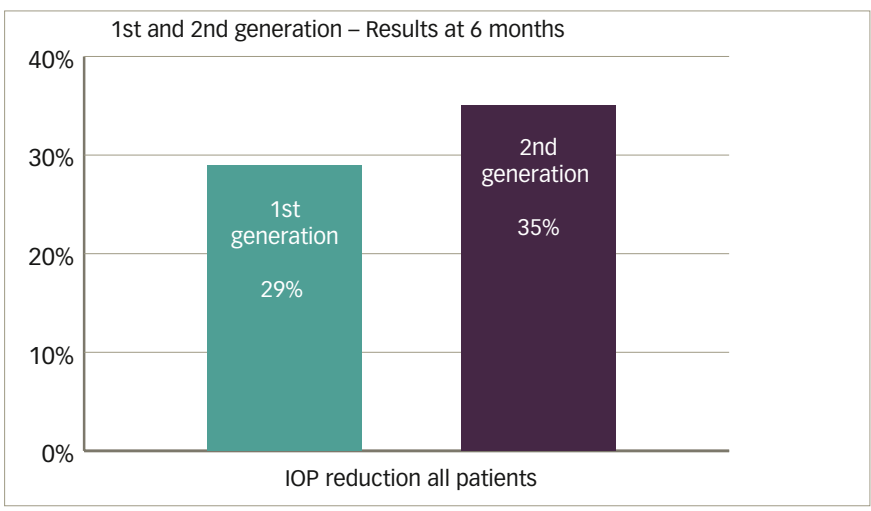

$I O P=$ intraocular pressure.

generation probe at $29 \%$. The success rate, defined as IOP reduction of at least $20 \%$ compared to baseline with no medication added, was 
Figure 4: Complete success rate of first- and secondgeneration at 6 months

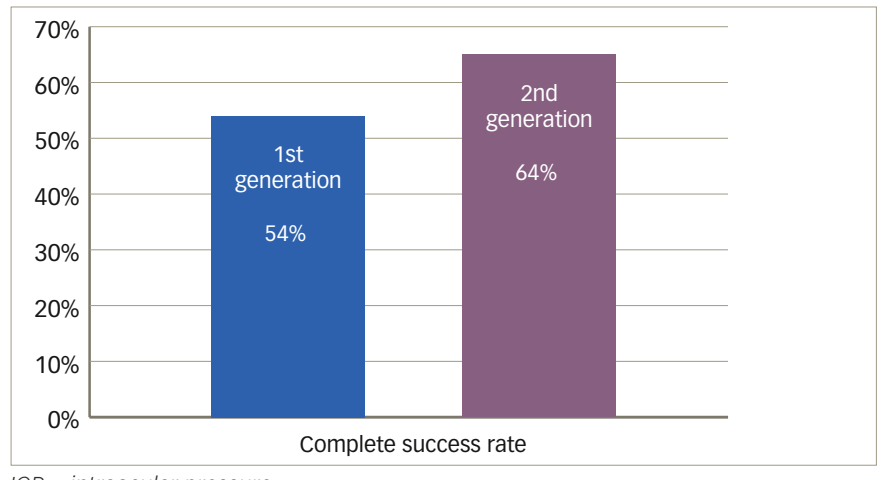

IOP = intraocular pressure

$54 \%$ for the first-generation and $64 \%$ for the second-generation probe, respectively (see Figure 4) (the p-value indicates a trend to a higher responder rate for the second-generation).

Figure 5 shows the IOP evolution in refractory and non-refractory. The average IOP reduction is 31\% for refractory and $33 \%$ for surgery-naive patients, respectively, at 6 months. There was no statistical difference in the response rate and in the relative IOP reduction between refractory and non-refractory glaucoma for both product generations. Figure 6 depicts the scattergram of the first-generation (A) and the secondgeneration (B) in terms of IOP reduction. As can be clearly seen from the much lower scattering of the data for the second-generation, the reproducibility for the treatment with this enhanced probe has been increased significantly. At 6-months follow-up, the second-generation probe was associated with a higher mean IOP reduction of $35 \%$ versus $29 \%$ for the first-generation.

\section{Safety}

The number and proportion of patients who experienced intra- and postoperative complications with the second-generation compared with the first-generation probe is shown in Table 2. Conjunctival hyperaemia was observed in 175 (69\%) patients; this was attributed to the placement of the suction cone and was frequently pre-existing from long-term treatment with medications. Inflammation due to the treatment, such as superficial punctate keratitis and anterior chamber reaction was also frequently observed, with a total of 61 (24\%) and 53 (21\%) patients, respectively.

Scleral marks - which were brownish spots at the ultrasound entry point, appearing for one or more sectors - were reported in 26 (10\%) patients. However, scleral marks were not analysed consistently in the studies of the first-generation probe. A trend was noted that scleral marks were more common in Indian eyes than in Caucasian eyes, which may be attributed to the more darkly pigmented sclera. There was variation in the pattern of scleral mark development: in some cases, the marks faded over time, whereas in other cases the reverse occurred. No scleral thinning could be observed on OCT and surgeons reported that there was no impact on carrying out filtering surgery if it was later required.

There were 20 (8\%) patients with corneal oedema, all pre-existing due to compromised fragile corneas in patients with refractory glaucoma and high baseline IOP. Twenty patients reported pain, mostly on the day(s) following the procedure, and sometimes required analgesia (once or twice a day).
Table 2: Meta-analysis safety results for first- and secondgeneration probes in all indications

\begin{tabular}{|c|c|c|c|c|c|c|}
\hline & \multicolumn{2}{|c|}{$\begin{array}{l}\text { 1st } \\
\text { generation } \\
\text { probe }\end{array}$} & \multicolumn{2}{|c|}{$\begin{array}{l}\text { 2nd } \\
\text { generation } \\
\text { probe }\end{array}$} & \multicolumn{2}{|c|}{ Total } \\
\hline & n & $\%$ & $\mathbf{n}$ & $\%$ & n & $\%$ \\
\hline Patients & 141 & & 110 & & 251 & \\
\hline \multicolumn{7}{|l|}{ Intraoperative } \\
\hline Ocular pain & 4 & $3 \%$ & 0 & $0 \%$ & 4 & $2 \%$ \\
\hline Corneal burn & 0 & $0 \%$ & 0 & $0 \%$ & 0 & $0 \%$ \\
\hline Subcunjonctival haemorrhage & 6 & $4 \%$ & 8 & $7 \%$ & 14 & $6 \%$ \\
\hline \multicolumn{7}{|l|}{ Postoperative } \\
\hline Conjunctival hyperemia ( $<7$ days) & 86 & $61 \%$ & 87 & $79 \%$ & 173 & $69 \%$ \\
\hline Superficial punctate keratitis & 44 & $31 \%$ & 17 & $15 \%$ & 61 & $24 \%$ \\
\hline Anterior chamber reaction ( $>7$ days) & 41 & $29 \%$ & 12 & $11 \%$ & 53 & $21 \%$ \\
\hline Transient ocular pain & 13 & $9 \%$ & 7 & $6 \%$ & 20 & $8 \%$ \\
\hline Corneal oedema* & 16 & $11 \%$ & 4 & $4 \%$ & 20 & $8 \%$ \\
\hline Corneal ulcer & 1 & $1 \%$ & 0 & $0 \%$ & 1 & $0 \%$ \\
\hline Corneal abrasion/epithelial defect & 1 & $1 \%$ & 3 & $3 \%$ & 4 & $2 \%$ \\
\hline Chemosis & 7 & $5 \%$ & 0 & $0 \%$ & 7 & $3 \%$ \\
\hline Transient macular oedema & 3 & $2 \%$ & 1 & $1 \%$ & 4 & $2 \%$ \\
\hline Astigmatism & 1 & $1 \%$ & 2 & $2 \%$ & 3 & $1 \%$ \\
\hline Goniosynechiae & 1 & $1 \%$ & 0 & $0 \%$ & 1 & $0 \%$ \\
\hline Scleral marks & 4 & $3 \%$ & 22 & $20 \%$ & 26 & $10 \%$ \\
\hline Irido-crystalline synechiae & 1 & $1 \%$ & 0 & $0 \%$ & 1 & $0 \%$ \\
\hline Early hypertonia (> 10mmHg) & 4 & $3 \%$ & 0 & $0 \%$ & 4 & $2 \%$ \\
\hline Early transient hypotonia ( $<6 \mathrm{mmHg}$ ) & 0 & $0 \%$ & 1 & $1 \%$ & 1 & $0 \%$ \\
\hline $\begin{array}{l}\text { Early transient hypotonia with } \\
\text { choroidal detachment }\end{array}$ & 2 & $1 \%$ & 1 & $1 \%$ & 3 & $1 \%$ \\
\hline Mydriasis & 0 & $0 \%$ & 1 & $1 \%$ & 1 & $0 \%$ \\
\hline Minor pupil peaked & 0 & $0 \%$ & 7 & $6 \%$ & 7 & $3 \%$ \\
\hline Loss of visual acuity (> 2 lines) & 6 & $4 \%$ & 0 & $0 \%$ & 6 & $2 \%$ \\
\hline Phthisis bulbi & 0 & $0 \%$ & 0 & $0 \%$ & 0 & $0 \%$ \\
\hline Cataract induced & 0 & $0 \%$ & 0 & $0 \%$ & 0 & $0 \%$ \\
\hline Hypotonia $(<6 \mathrm{mmHg})$ & 0 & $0 \%$ & 0 & $0 \%$ & 0 & $0 \%$ \\
\hline
\end{tabular}

* Patients with high intraocular pressure prior to treatment and pre-existing compromised fragile cornea.

Serious complications are listed in Table 3. Transient macular oedema, occurring in four patients (2\%), were treated by steroids and resolved in a few months without a further decline in visual acuity. More research is required to determine the cause of this serious complication and its relation to UCP treatment. Corneal abrasions/epithelia defects, also occurring in four patients, healed several weeks after treatment. It is supposed that they were caused by touching the cornea with the suction cone during positioning. Hypotony with choroidal detachment was a transient adverse effect that resolved within 1 month in all cases after steroid treatment. IOP-reducing medications were removed in these cases. Induced astigmatism occurred in three patients (1\%) and improved over 3-6 months. Minor pupil irregularities were observed in seven patients (3\%).

\section{Discussion}

The HIFU delivery device was effective in decreasing IOP in patients with non-refractory and refractory glaucoma, in this meta-analysis 
Figure 5: Mean intraocular pressure reductions for refractory and non-refractory glaucoma - all probe generations
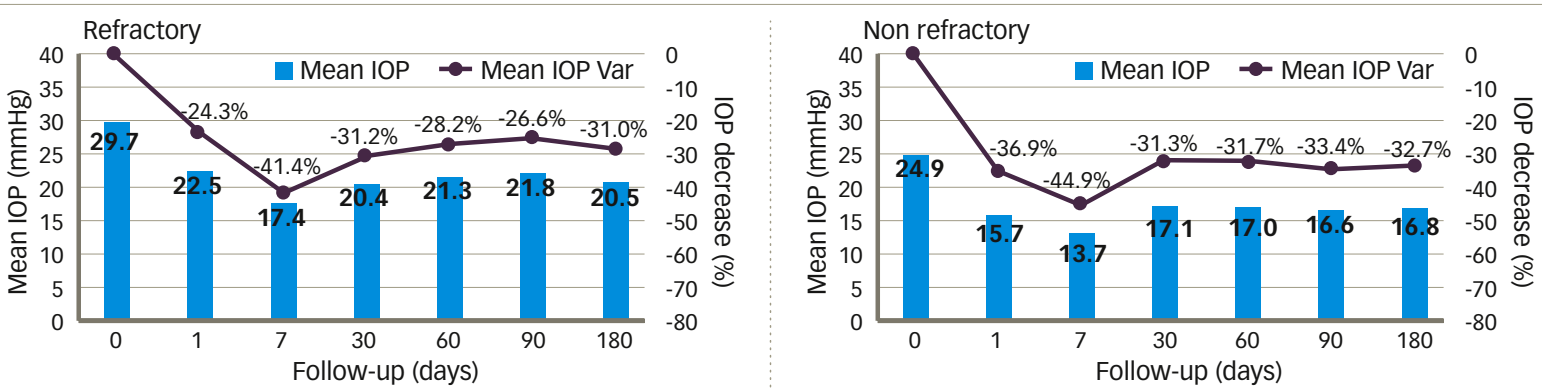

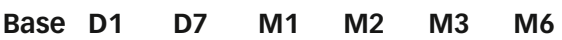

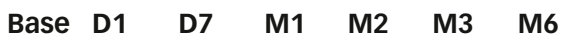

$\begin{array}{lllllll}133 & 117 & 130 & 131 & 77 & 120 & 108\end{array}$

Pts

$\begin{array}{lllllll}118 & 111 & 118 & 116 & 111 & 114 & 108\end{array}$

\begin{tabular}{|c|c|c|c|}
\hline & 3.6 & 3.5 & 3 \\
\hline
\end{tabular}

Med.

$\begin{array}{lllllll}1.6 & 1.5 & 1.6 & 1.6 & 1.4 & 1.5 & 1.6\end{array}$

$D=$ day; IOP = intraocular pressure; Med = glaucoma medication; $P$ ts = patients; Var = variation.

Table 3: Serious complications reported in patients across seven clinical studies $(n=251)$

\begin{tabular}{|l|l|}
\hline Serious complication & $n$ \\
\hline Loss of visual acuity (> 2 Snellen lines) & 6 \\
\hline Transient macular oedema & 4 \\
\hline $\begin{array}{l}\text { Corneal abrasion - epithelial defect mechanical effect due to } \\
\text { placement of cone }\end{array}$ & 4 \\
\hline Hypotony with choroidal detachment & 3 \\
\hline Induced astigmatism & 3 \\
\hline
\end{tabular}

of seven controlled clinical studies. The safety of the procedure and good pre- and postoperative patient tolerance is encouraging. Serious complications were rare. In particular, persistent hypotony, phthisis bulbi, or induced cataract were not observed. The cause of loss of visual acuity observed in a few patients is not yet clear, but is possibly related to glaucoma progression in patients with advanced disease. Similarly, the causes of induced astigmatism and pupil irregularities are uncertain but may be related to cases where the ultrasound probe was too close to the limbus. The risk of early hypertension is low but cannot be ruled out; indeed, this has been reported in cyclodestructive techniques such as cyclocryotherapy. ${ }^{10}$ IOP was measured at the first postoperative visit (usually day 1), however, the IOP immediately after the procedure has not yet been measured.

The superior reproducibility of the second-generation probe over the original version (see Figure 4) was likely achieved by improved positioning of the probe and a revised design to avoid air bubbles in the coupling liquid that can cause cold spots as the ultrasound energy is not transmitted from the transducer into the tissue. In addition, the increased transducer size permits treatment of a larger proportion of the ciliary body, which stays below $40 \%$ of the circumference. This also allows for anatomical variation in the ciliary body to be taken into account. These enhancements have led to an increase in efficacy and reproducibility of the outcome.

\section{Practical considerations}

The treatment is CE-marked and used in routine clinical practice for refractory glaucoma after a failed filtering surgery. Recent study results on surgery-naive patients with a 12-month follow-up show that there is no statistical difference in outcome compared to that in refractory glaucoma patients following unsuccessful filtering surgery. ${ }^{8,11}$ These findings are consistent with those from the present analysis (see Figure 3). Based on
Figure 6: Scatterplot showing intraocular pressure before and after UCP treatment for both first- and secondgeneration products at 6 months

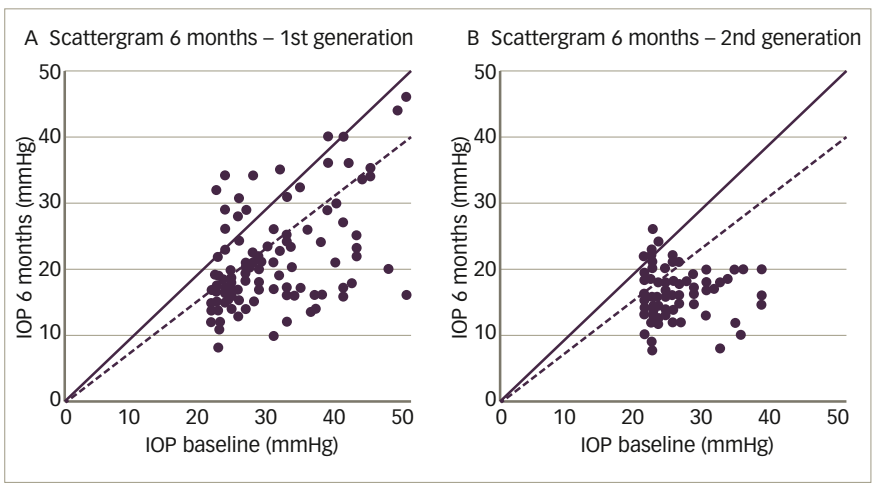

$I O P=$ intraocular pressure; $U C P=$ ultrasound ciliary plasty

these data the CE mark was extended to non-refractory patients and the recommended patient profile is as follows:

- Patient between 18 and 90 years old, male or female, able and willing to be followed up at 7 days, 1 month, 3 months, 6 months, 12 months, and every 6 months thereafter.

- Primary OAG (POAG) including pigmentary glaucoma and pseudoexfoliative glaucoma.

- Any patient having previously failed filtration surgery or patients having an elevated risk for surgical failure.

- Patients having an IOP which is not adequately controlled with maximally tolerated glaucoma medication, with IOP $\geq 21 \mathrm{mmHg}$ and IOP $<35 \mathrm{mmHg}$.

- UCP shall not be performed earlier than 90 days after previous intraocular surgery or laser treatment.

Biometric assessment is required to determine the probe size and diameter of the ciliary body during pre-treatment diagnostics. Options for such assessment include OCT, UBM or optical measurement of White-To-White and axial length or combinations thereof. Despite this simple step, special care shall be taken to determine the probe diameter and the centring on the globe. A uniform white ring has to be visible upon placement of the suction cone prior to placing the ultrasound probe inside. This will avoid directing the ultrasound beam too close to the limbus. In ambiguous cases it is recommended to choose the larger probe size. 
The technology allows flexibility in choosing the site of service for the UCP procedure and it can be administered in an operating room or in a treatment room, for example, for intravitreal injections. Local policies, logistics, and reimbursement conditions have to be considered.

As a topical anaesthesia is not sufficient to avoid pain, in many cases the current practice can be divided into local anaesthesia by means of peri-/or retrobulbar block, topical anaesthesia with intravenous analgesics, or in some cases general anaesthesia at patient request. In case of retrobulbar block, a mydriasis has been observed that is not linked to the ultrasound procedure itself and can be avoided by administering pilocarpine 30-60 minutes prior to the procedure.

Patients should be observed for about two hours after the procedure. Anti-inflammatory agents (steroids) should be administered over three to four weeks and, depending on local guidelines, mydriatic agents may be used over 1-2 weeks. The patient should be followed-up within the first week after the procedure and about 1 month afterwards. A definitive reduction in IOP cannot be confirmed before 2 months after the procedure as, for example, anti-inflammatory agents given over
4 weeks might impact on IOP. Usually, glaucoma medication should be maintained until the second month and then adjusted, depending on the actual pressure compared to treatment target.

One re-treatment procedure is possible but not recommended until three months postoperatively, provided the IOP is not sufficiently controlled after one procedure and the patient is complication free. It is also recommended to reassess the diameter of the probe required to exclude ambiguities because this is the major source for errors. Other treatment (selective laser trabeculoplasty, filtering surgery, cyclo-destruction diode laser) is possible in case of an unsuccessful UCP treatment but should not be considered before 2 months. Should UCP be unsuccessful in a surgery-naive patient, it is recommended to pass on to filtering surgery prior to any cyclodestructive method such as laser photocoagulation.

In summary, UCP with high-intensity focused ultrasound delivered by miniaturised high-frequency transducers appears to be a promising, effective treatment for reducing IOP in patients with refractory and nonrefractory OAG. Further clinical research is ongoing to study the IOP evolution at longer follow-up with the second-generation probe. $\mathrm{J}$
1. Aptel F, Charrel T, Palazzi $X$, et al., Histologic effects of a new device for high-intensity focused ultrasound cyclocoagulation, Invest Ophthalmol Vis Sci, 2010:51:5092-8.

2. Charrel T, Aptel F, Birer A, et al., Development of a miniaturized HIFU device for glaucoma treatment with conformal coagulation of the ciliary bodies, Ultrasound Med Biol, 2011;37:742-54

3. Aptel F, Charrel T, Lafon C, et al., Miniaturized high-intensity focused ultrasound device in patients with glaucoma: a clinica pilot study, Invest Ophthalmol Vis Sci, 2011;52(12):8747-53.

4. Denis P, Aptel F, Rouland JF, et al., Cyclocoagulation of the ciliary bodies by high-intensity focused ultrasound: a 12-month multicenter study, Invest Ophthalmol Vis Sci, 2015;56:1089-96.
5. Melamed S, Goldenfeld M, Cotlear D, et al., High-intensity focused ultrasound treatment in refractory glaucoma patients: results at 1 year of prospective clinical study, Eur J Ophthalmol 2015;25:483-9

6. Aptel F, Dupuy C, Rouland JF, Treatment of refractory open-angle glaucoma using ultrasonic circular cyclocoagulation: a prospective case series, Curr Med Res Opin, 2014;30:1599-605

7. Rouland JFA, Primary Open Angle Glaucoma treated by High Intensity Focused Ultrasound (HIFU) with 2nd generation probe. Presented at: European Association For Vision and Eye Research (EVER); 7-10 October; Nice, France, 2015.

8. Aptel F, Denis P, Rouland JF, et al., Multicenter clinical trial of high-intensity focused ultrasound treatment in glaucoma patients without previous filtering surgery, Acta Ophthalmol 2016;94:e268-77.

9. Fogagnolo P. Digiuni M, Maggiolo E, Rossetti LM, Clinical efficacy of ultrasonic circular cyclo coagulation in refractory glaucoma. Preliminary results. Presented at: Association for Research in Vision and Ophthalmology (ARVO) Annual Meeting; May 5-9, 2013; Seattle, Washington, USA, 2013

10. Minckler DS, Tso MO, Experimental papilledema produced by cyclocryotherapy, Am J Ophthalmol, 1976;82:577-89.

11. Deb N, Pagidimarry N, Bhatnagar V, Prasad Reddy K, Application of High Intensity Focused Ultrasound (HIFU) for treatment of primary open angle glaucoma in Indian patients. Presented at: Congress of Glaucoma Society of India; October 2nd-4th, 2015 Mumbai, India, 2015. 